\title{
$N N^{\prime}$-Diacetylchitobiase Activity in Tay-Sachs Disease and Sandhoff's Disease
}

\author{
By JoHn L. STIRLING \\ Department of Biochemistry, Queen Elizabeth College (University of London), \\ Campden Hill Road, London W8 7AH, U.K.
}

(Received 2 May 1974)

\begin{abstract}
In Tay-Sachs disease and Sandhoff's disease respectively, one of the $N$-acetyl- $\beta$-hexosaminidases (form A) or both (forms A and B) are absent, but glycosaminoglycans containing $N$-acetylhexosamines are not accumulated. The presence of $N N^{\prime}$-diacetylchitobiase in livers from patients with these diseases raises the possibility that this new enzyme is involved in the metabolism of glycosaminoglycans rather than the enzymes previously described.
\end{abstract}

The disaccharide $N N^{\prime}$-diacetylchitobiose is hydrolysed by two main enzyme activities in extracts of human liver. $N$-Acetyl- $\beta$-hexosaminidase accounts for about one-quarter of the activity, the rest being due to an enzyme of low molecular weight which is readily distinguished from hexosaminidase by its inability to hydrolyse aryl $N$-acetyl- $\beta$-hexosaminides (Stirling, 1974). This enzyme, chitobiase, is therefore undetected in assays for hexosaminidase using synthetic substrates.

Two major forms of $N$-acetyl- $\beta$-hexosaminidase, $A$ and $B$, occur in human tissues (Robinson \& Stirling, 1968; Dance et al., 1969), and their contribution to the turnover of glycoproteins, glycolipids and glycosaminoglycans can be assessed by relating the nature of the storage product to the enzyme defect in Tay-Sachs disease and Sandhoff's disease. In Tay-Sachs disease the absence of hexosaminidase A leads to accumulation of the ganglioside $\mathrm{GM}_{2}$ in brain, but glycosaminoglycans are unaffected (O'Brien et al., 1970). Hexosaminidases A and $B$ are both missing in Sandhoff's disease, and globoside and asialoganglioside $\mathbf{G M}_{2}$ accumulate in the kidneys in addition to storage of ganglioside $\mathrm{GM}_{2}$ in brain, but there does not appear to be storage of glycosaminoglycans (Strecker \& Montreuil, 1971; Applegarth \& Bozoian, 1972).

That the absence of a glycosidase can lead to storage of glycosaminoglycans is demonstrated in Sanfillipo disease type $B$ in which the accumulation of heparan sulphate is due to the absence of $N$-acetyl- $\alpha$-glucosaminidase (O'Brien, 1972). By analogy it would appear that hexosaminidases $A$ and $B$ are not involved in the metabolism of glycosaminoglycans, since their absence does not lead to accumulation of these substances. Presumably glycosaminoglycans are degraded by another pathway involving an enzyme capable of hydrolysing $\beta$ - $N$-acetylhexosaminyl linkages in natural substrates but not the aryl derivatives commonly used to detect hexosaminidases. Chitobiase is a possible candidate for this role, but its activity would have to be unimpaired in both Tay-Sachs and Sandhoff's diseases. In this communication the detection of chitobiase in liver from patients with Tay-Sachs disease and Sandhoff's disease is described.

\section{Materials and methods}

Samples of livers from cases of Tay-Sachs disease and Sandhoff's disease, generously provided by Dr. R. Tateson and Dr. A. D. Bain, Royal Hospital for Sick Children, Edinburgh, were stored at $-15^{\circ} \mathrm{C}$ until required. Normal liver samples were obtained at post-mortem and also stored at $-15^{\circ} \mathrm{C}$. Chitin was purchased from Eastman Kodak Ltd., Kirby, Lancs., U.K., and 4-methylumbelliferyl 2acetamido-2-deoxyglucopyranoside was from KochLight Laboratories, Colnbrook, Bucks., U.K. Sephadex G-100 was purchased from Pharmacia (G.B.) Ltd., London W.5, U.K. All reagents were analytical grade.

A full description of the method used to prepare $N N^{\prime}$-diacetylchitobiose has been published (Stirling, 1974). Briefly, the disaccharide was isolated from an $\mathrm{HCl}$ hydrolysate of chitin $(20 \mathrm{~g})$ by chromatography on a column $(4.5 \mathrm{~cm} \times 75 \mathrm{~cm})$ of charcoal-Celite (Rupley, 1964). Fractions were monitored by t.l.c. on $0.25 \mathrm{~mm}$-thick layers of silica gel $\mathbf{G}$ (Anderman and Co. Ltd., London S.E.1, U.K.) developed in propan-1-ol-water $(7: 3, v / v)$, and those which contained the disaccharide were pooled and concentrated to give a crude chitobiose preparation. Saccharides were detected with the acid permanganate reagent described by Powning \& Irzykiewicz (1967). Further purification was obtained by chromatography of this crude preparation on a column $(2.6 \mathrm{~cm} \times 79 \mathrm{~cm})$ of Sephadex LH20 in water, and those fractions which gave a single spot of chitobiose on t.l.c. were evaporated to dryness.

Chitobiase was assayed at $37^{\circ} \mathrm{C}$ by incubating $100 \mu \mathrm{l}$ of solution containing the enzyme with $100 \mu \mathrm{l}$ of $10 \mathrm{~mm}$-chitobiose in Mcllvaine (1921) sodium 
phosphate-citrate buffer, $\mathrm{pH} 3.5$. After a suitable incubation period ( $2 \mathrm{~h}$ for column fractions) the reaction was stopped by adding $100 \mu \mathrm{l}$ of $0.8 \mathrm{M}$ potassium tetraborate, $\mathrm{pH} 9.1$, and boiling for exactly $3 \mathrm{~min}$ in capped tubes. The tubes were cooled in icewater, $3 \mathrm{ml}$ of $p$-dimethylaminobenzaldehyde reagent was added (Reissig et al., 1955) and the colour allowed to develop for $15 \mathrm{~min}$ at $37^{\circ} \mathrm{C}$ before the extinction at $545 \mathrm{~nm}$ was read. $N$-Acetyl- $\beta$-hexosaminidase was assayed by the method of Dance et al. (1969).

Liver extracts were made by chopping $5 \mathrm{~g}$ of tissue into a fine mince with scissors and homogenizing this in $10 \mathrm{ml}$ of $0.01 \mathrm{M}$-sodium citrate buffer, $\mathrm{pH} 4.5$, with a Teflon-in-glass homogenizer. The homogenates were centrifuged at $38000 \mathrm{~g}$ for $30 \mathrm{~min}$ at $4^{\circ} \mathrm{C}$ in an MSE 18 centrifuge to give supernatants which were used for gel-permeation chromatography. Samples of liver extract were applied to a column $(2.6 \mathrm{~cm} \times 35 \mathrm{~cm})$ of Sephadex G-100 equilibrated with $0.01 \mathrm{M}$-sodium citrate buffer, $\mathrm{pH} 4.5$, and eluted at a flow rate of $25 \mathrm{ml} / \mathrm{h}(2.5 \mathrm{ml}$ fractions).

\section{Results}

$N$-Acetyl- $\beta$-hexosaminidase and chitobiase were assayed in extracts of normal liver and livers from patients who had died from Tay-Sachs and Sandhoff's diseases. The results of these assays are shown in Table 1.

Identical procedures were used for the preparation of the liver extracts, and the conditions used for chromatography on Sephadex G-100 and assay of the column fractions were the same so that a direct comparison of the elution profiles can be made (Fig. 1). $N$-Acetyl- $\beta$-hexosaminidase was eluted as a single peak of activity when extracts of normal liver and liver from a patient with Tay-Sachs disease were chromatographed, but the activity in an extract of liver from a patient with Sandhoff's disease was too low to be detected in the fractions after chromatography.

Chitobiase was eluted in three main forms that were distinguished by their molecular size and their

Table 1. $N$-Acetyl- $\beta$-hexosaminidase and chitobiase activities in normal liver from patients with Tay-Sachs and Sandhoff's diseases

Activities are expressed as nmol of substrate hydrolysed/ min per $\mathrm{g}$ wet wt. of tissue.

$\begin{array}{ccl}\text { Liver } & \begin{array}{c}\text { hexosaminidase } \\ \text { activity }\end{array} & \begin{array}{c}\text { Chitobiase } \\ \text { activity }\end{array} \\ \text { Sal } & 89.6 \pm 30.6(5) & 33.1 \pm 5.4(5) \\ \text { Sachs disease } & 157.5 & 58 \\ \text { hoff's disease } & 7.0 & 67\end{array}$
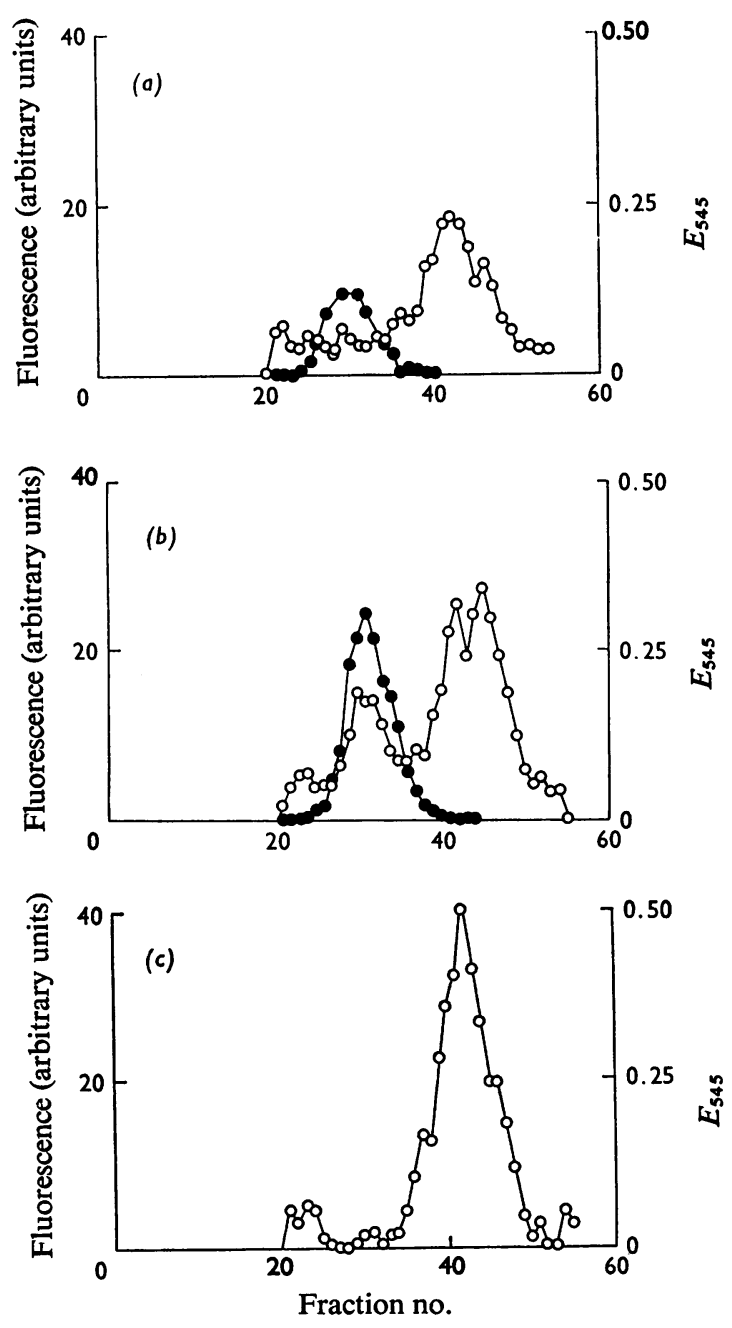

Fig. 1. Separation of $N$-acetyl- $\beta$-hexosaminidase and chitobiase on Sephadex G-100 equilibrated in $0.01 \mathrm{M}-$ sodium citrate buffer, $\mathrm{pH} 4.5$

(a) Normal liver; (b) liver from Tay-Sachs patient; (c) liver from Sandhoff's patient. Fractions $(2.4 \mathrm{ml})$ were collected. $N$-Acetyl- $\beta$-hexosaminidase activity $(0)$ is given in fluorescence units and chitobiase activity $(\mathrm{O})$ as $E_{545}$. The assays are described in the text.

relationship to hexosaminidase in the elution profile. A small peak of chitobiase, free from hexosaminidase, was eluted along with the Blue Dextran used to indicate the void volume. All three liver extracts had this component. In normal liver the chitobiase associated with the hexosaminidase peak appeared as an ill-defined spread of activity (Fig. 1a), but in other liver samples this was present as a more definite peak (Stirling, 1974). The extract 
from the liver of a patient with Tay-Sachs disease (Fig. 1b) had a clear peak of chitobiase activity associated with the hexosaminidase, but in the extract from the liver of a patient with Sandhoff's disease (Fig. 1c) this component was decreased to a very low value. The major chitobiase peak showed some variation between the three samples, with the major part of the activity being recovered in a single peak in normal liver, a double peak in liver from the patient with Tay-Sachs disease and a single fairly symmetrical peak in liver from the patient with Sandhoff's disease. These differences in the form of the chitobiase peak may be fortuitous, since chitobiase from normal liver has a variable elution pattern from Sephadex G-100, and this seems to be influenced by the nature of the buffer used as the eluent (Stirling, 1974).

\section{Discussion}

There have been several reports to the effect that glycosaminoglycans do not accumulate in either Tay-Sachs or Sandhoff's diseases (O'Brien et al., 1970; Applegarth \& Bozoian, 1972; Strecker \& Montreuil, 1971), and thus it appears that degradation of glycosaminoglycans is not dependent on the expression of either hexosaminidase A or B activities. However, Thompson et al. (1973) found that extracts of fibroblasts from Tay-Sachs and Sandhoff's patients were unable to hydrolyse a heptasaccharide from chondroitin 4-sulphate specifically labelled in the terminal $N$-acetylgalactosamine group, although the activity was readily detected in extracts from normal cells. They suggested that hexosaminidase A is responsible for the hydrolysis of the oligosaccharide but were unable to explain why a lack of the enzyme in Tay-Sachs and Sandhoff's diseases does not result in accumulation of glycosaminoglycans.

The results given in this communication show that an oligosaccharase, detected by its activity towards $N N^{\prime}$-diacetylchitobiose, is present in the liver of patients with Tay-Sachs disease and Sandhoff's disease as well as in normal liver. It seems possible that this enzyme could be involved in the degradation of glycosaminoglycan oligosaccharides, its presence in the diseased tissues providing an explanation for the normal metabolism of these substances.

Since fibroblasts from patients with Tay-Sachs and Sandhoff's diseases were unable to hydrolyse the heptasaccharide used by Thompson et al. (1973), it appears that chitobiase does not act on this substrate.
However, the predominant products resulting from the concerted action of hyaluronidase and $\beta$ glucuronidase on hyaluronic acid and chondroitin 4-sulphate are trisaccharides with a non-reducing $\beta$ - $N$-acetylhexosaminyl end group (Weissmann $e t$ al., 1964), and these small oligosaccharides may be more suitable substrates for an oligosaccharase than the heptasaccharide.

The relationship between chitobiase and $N$-acetyl$\beta$-hexosaminidase is clarified by the Sephadex G-100 elution profile of liver from the patient with Sandhoff's disease. Loss of both hexosaminidase activity and the chitobiase activity associated with the peak in normal liver and liver from the Tay-Sachs patient suggests that these activities are catalysed by the same enzyme and that chitobiase activity present in other column fractions, obtained with all of the liver samples (Fig. 1), is the product of a different gene.

In Tay-Sachs disease all the hexosaminidase is of the $B$ form and there is an increase in the chitobiase activity associated with this peak. This may be due to hexosaminidase B having a higher ratio of chitobiase activity to hexosaminidase activity than hexosaminidase A or may reflect the instability of form A relative to chitobiase under the respective assay conditions.

My thanks are due to Professor D. Robinson for his advice and encouragement and to Pamela Rendle for valuable technical assistance.

Applegarth, D. A. \& Bozoian, G. (1972) Clin. Chim. Acta 39, 269-271

Dance, N., Price, R. G., Robinson, D. \& Stirling, J. L. (1969) Clin. Chim. Acta 24, 189-197

McIlvaine, T. C. (1921) J. Biol. Chem. 49, 183-186

O'Brien, J. S. (1972) Proc. Nat. Acad. Sci. U.S. 69, 1720 1722

O'Brien, J. S., Okada, S., Ho, M. W., Fillerup, D. L. \& Veath, M. L. (1970) Fed. Proc. Fed. Amer. Soc. Exp. Biol. 30, 956-969

Powning, R. E. \& Irzykiewicz, H. (1967) J. Chromatogr. 29, 115-119

Reissig, J. C., Strominger, J. L. \& Leloir, L. F. (1955) J. Biol. Chem. 217, 959-966

Robinson, D. \& Stirling, J. L. (1968) Biochem. J. 107, 321-327

Rupley, J. A. (1964) Biochim. Biophys. Acta 83, 245-255

Stirling, J. L. (1974) FEBS Lett. 39, 171-175

Strecker, G. \& Montreuil, J. (1971) Clin. Chim. Acta 33, 395-401

Thompson, J. N., Stoolmiller, A. C., Matalon, R. \& Dorfman, A. (1973) Science 181, 866-867

Weissmann, B., Hadjioannou, S. \& Tornheim, J. (1964) J. Biol. Chem. 239, 59-63 